\title{
PReS-FINAL-2150: Antiocular antibodies in children with juvenile idiopathic arthritis-associated uveitis
}

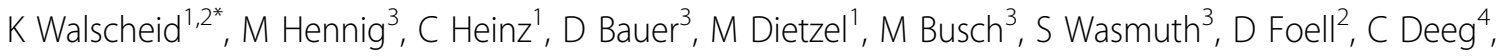 \\ A Heiligenhaus $^{1}$
}

From 20th Pediatric Rheumatology European Society (PReS) Congress

Ljubljana, Slovenia. 25-29 September 2013

\section{Introduction}

Juvenile idiopathic arthritis (JIA) is the most common disease associated with uveitis of childhood. The pathogenesis of JIA-associated uveitis (JIAU) is undefined, although there is evidence for a B-cell-mediated autoimmune process with a probably pathogenetic role for autoantibodies.

\section{Objectives}

This study intended to analyze the antiocular autoantibodies in serum and their correlation with disease course.

\section{Methods}

Serum samples from children with JIAU $(\mathrm{n}=47)$, JIA without uveitis $(n=67)$, idiopathic anterior uveitis (IAU, $\mathrm{n}=12)$ and healthy controls $(\mathrm{n}=52)$ were collected. The binding patterns of serum antibodies to ocular cryosections from swine eyes were analyzed by indirect immunohistochemistry, and were correlated to epidemiological, clinical and laboratory test results.

\section{Results}

The patient groups differed with respect to their presence of antibody-binding to the sections: JIAU (94\%), JIA (75\%), IAU (75\%), and healthy controls (29\%) to uveal and/or retinal structures. Serum antibodies of JIAU patients predominantly bound at iris (74\%) and ciliary body (cb, 79\%). Iris/ $\mathrm{cb}$ positive staining correlated with the presence of uveitis complications $(\mathrm{p}<0.005)$ in JIAU patients, but not with positivity for serum anti-nuclear antibodies (ANA), rheumatoid factor (RF) or HLA-B27, and was independent from uveitis activity or type of anti-inflammatory treatment.

\section{Conclusion}

In JIAU patients, anti-ocular serum antibodies can be detected more frequently than in control groups. Binding patterns to ocular tissue correlate with complicated uveitis course but not with uveitis activity and anti-inflammatory treatment. Antibody-binding is not specific for this uveitis entity, and does not correlate with ANA-positivity.

\section{Disclosure of interest}

None declared.

\section{Authors' details}

'Department of Ophthalmology, St. Franziskus-Hospital Muenster, Muenster, Netherlands. ${ }^{2}$ Department of Pediatric Rheumatology and Immunology, University Hospital Muenster, Muenster, Netherlands. ${ }^{3}$ Ophtha-Lab; Department of Ophthalmology, St. Franziskus-Hospital Muenster, Muenster, Netherlands. ${ }^{4}$ Department of Animal Physiology, Ludwig Maximilians University Munich, Munich, Germany.

Published: 5 December 2013
doi:10.1186/1546-0096-11-S2-P162

Cite this article as: Walscheid et al:: PReS-FINAL-2150: Antiocular antibodies in children with juvenile idiopathic arthritis-associated uveitis. Pediatric Rheumatology 2013 11(Suppl 2):P162. 